\title{
A Study to Evaluate the Incidence of Cholelithiasis in Damwi, Balghami, Safrawi and Saudawi Temperament
}

\author{
Jan $A^{1 *}$, Iqbal $A^{2}$, Ali Quraishi $H^{3}$, Zahoor $S^{4}$, Mushtaq $S^{5}$ and Hussain $A^{6}$ \\ ${ }^{1}$ Assistant Professor, Physiology-IAMS, Unani Medical College, Srinagar, India \\ ${ }^{2}$ Resarch Officer, RRIUM, (CCRUM- Ministry of AYUSH), Srinagar, India \\ ${ }^{3}$ MD Scholar Unani Medicine, (CCRUM- Ministry of AYUSH), Srinagar, India \\ ${ }^{4}$ Medical Officer ISM, J \& K Health Service, Kashmir, India \\ ${ }^{5}$ Assistant Professor, Medicine, IAMS, Unani Medical College, Srinagar, India \\ ${ }^{6}$ Prof. Deoband Unani Medical College, Deoband, India
}

\section{Research article \\ Volume 5 Issue 1}

Received Date: March 31, 2020

Published Date: May 15, 2020

DOI: $10.23880 /$ ijbp-16000174

*Corresponding author: Afroza Jan, Department of Physiology- IAMS, Unani Medical College, Srinagar, India, Tel: +91 9796727000; Email: afroze.dr@gmail.com

\section{Abstract}

Gallstones occurs when the amount of cholesterol or bilirubin is high in bile and bile form solid particles in the gall bladder. Gallstones constitute a significant health problem and is a leading cause for hospital admission related to gastrointestinal problems. In majority of the cases the gallstone is silent and do not give any symptom such as acute cholecystitis, cholangitis or pancreatitis, however it is found as an incidental finding during abdominal ultrasound or by doing computed tomography scan. Cholelithiasis is a medico surgical problem for organ transplantation. In cholelithiasis the pain mechanism is usually obstruction located at gall bladder outlet, incoordination between gallbladder contraction and sphincter of oddi relaxation or visceral hypersensitivity. It may also be due to impaired gallbladder emptying, reliably quantitated by cholecystokinin cholescintigraphy. These are high chances of developing gall stones in chronic diseases like advanced cirrhosis, crohns disease, cystic fibrosis and sickle cell disease. Since Unani system of medicine is based on the health of humours (Ikhlat) Damwi, Balghami, Safrawi and Saudawi. The present work is an effort to establish association between risk factors and to observe the prevalence of gall-stone in social groups. The present study has been attempted with four different categories Damwi Bilious (Safravi) Phlegmatic (Balghami) and Saudawi temperament individuals because these two categories show different types of signs and symptoms as their physiological, physical, and psychological features and are opposite to each other on the basis of their Hot and Cold temperament respectively. Hence is has been observed that incidence of formation of gallstone is according to different body temperaments which is high in Safrawi (Choleric/ bileous) fallowed by Balghami (Phlegmatic), Damwi (Sanguine) and Saudawi (Melancholic).

Keywords: Gallstone; Cholelithiasis; Mizaj; Hisat-e-Marara; Unani Medicine

\section{Introduction}

Gallstone (Cholelithiasis) is a most common disease of female, in Unani medicine it is known as Hisat-e-Mararah/ Hisat-e-Kabid. It is a disease of extra hepatic biliary system, which constitutes hepatic ducts, common hepatic duct, cystic duct, gall bladder and common bile duct. It starts from the hilum of the liver and extends up to ampulla of Vater in the second part of duodenum. Functionally extra hepatic biliary system is concerned with drainage and storage of bile and excretion of it into gastrointestinal tract. Biochemically, bile is a solution containing bile acids. Cholesterol bindsitself loosely with phospholipids and lecithin to form clumps or micelles. These globular forms of micelles and cholesterol are held in solution by appropriate concentration of bile acids. Any disparity between bile acids and cholesterol concentration prevents suspensibility of cholesterol. Anatomically, gall bladder is the most susceptible part of extra hepatic biliary 


\section{International Journal of Biochemistry \& Physiology}

system for disease[1,2] and the most common disease of this organ is inflammation and this inflammation is usually associated with stones and sometimes it is precipitating cause of inflammation, thus a calculus as well as calcular inflammation is supposed to be bacterial. As far as formation of stones and associated changes in the gall bladder are concerned, they are almost fixed and well established. The prevalence rates in adult European is $10-15 \%$, while in African and 1 Asian populations prevalence is 3-5\%. The main cause of stone formation is disparity between concentration of cholesterol and bile acids. When cholesterol exceeds that of normal, micelles start to precipitate, and this precipitation of micelles of cholesterol is called as nucleation. Further addition of cholesterol around the nucleus enlarges the size of the stone. Contrary to this, if bile salts exceed in their Concentration, they tend to form crystals and when these crystals precipitate, they form pigment stones. The causative factors of stone formation may be grouped under the following major heads i.e. excess of cholesterol in bile, too much bilirubin in bile, inflammation of gall bladder mucosa which disturbs absorptive properties of gall bladder, absorption of water, excessive absorption of bile salts from bile.

Causes of cholelithiasis according to Greeco Arab scholar per Rabban Tabri (861) and Majoosi(1010), the main and 1st cause of gall stone formation is sudda (obstruction) in gall bladder [3,4]. Zakariya Razi (923) mentioned that jaundice is sometime due to hepatic and sometime due to obstruction, and the cause of obstruction is sticky fluid which is formed by fatty diet [5]. Ibn-e-Sina (1037) told that the causes of gall stone formation are dame ghaliz, Zoaf quate dafeya, shiddate jazba, congenital narrowing of biliary system, khilte ghaliz wa lazuj ghaliz ashiya, mitti chuna etc. Ibn-e-Hubal (1213) mentioned the same cause as by IbneSina with addition of two special diets, 1 . Hareesa (the meal prepared by meat and crushed wheat), 2. Aseeda (the meal prepared by ghee and flour) [6]. Nafis bin Awaz (1669) used the term "Hisat-ul-Kabid" in place of sudda kabid and told that causes of stone formation in liver are the same as the stone formation in kidney and urinary bladder [7]. As per Allama Akbar Arzani (1721) the cause of hepatic stone is sticky raw fluid [8]. Allama Kabiruddin (1976) described the detail of stone formation in liver e.g. Precipitation of bile, precipitation of bile salts in certain condition, altered ratio of bile salt and bile acids, sometime bacteria in the gall bladder act as nucleus for stone formation [9]. The overall etiological factors, whatever they may be, would cause any stone forming changes in bile. Some histological factors are related to the gall bladder itself. Some are metabolic, still others are concerned with sex age and region $[10,11]$. Till now various etiological factors have been described to have indefinite association with Cholelithiasis i.e. multiparity, obesity, female sex, luxurious lifestyle, excessive fat intake, deranged fat metabolism, low-grade cholecystitis, use of oral contraceptive drugs, fourth decade of life, intestinal disease especially absorption related hemolytic conditions, gall bladder disease, bile circulatory disturbances, biliary stasis due to obstruction in flow of bile due to any cause, parenteral alimentation, excess of calcium concentration in bile, bacterial infection [9,12]. Apolipo-protein A1 plays a crucial role for nucleation and antinucleation [13] in the pathogenesis of stone formation. Nucleating factors initiates stone formation, this group includes mucin, its secretion increases in inflammatory conditions under the influence of prostaglandin. Moreover, mucin in combination with bilirubin forms sludge which serves as stone initiator. Contrary to this anti-nucleating factor, probably lipoprotein A-1 prevents crystallization of cholesterol. Its respective gene determines the nature of anti-nucleating factor, and this proves the genetic predisposition for lithogenesity [8]. The present work is an effort to establish association between risk factors and to observe the prevalence of gall-stone in social groups. The present study has been attempted with four different categories Damwi Bilious (Safravi) Phlegmatic (Balghami) and Saudawi temperament individuals because these two categories show different types of signs and symptoms as their physiological, physical, and psychological features and are opposite to each other on the basis of their Hot and Cold temperament respectively.

\section{Epidemiology}

The bestepidemiological screening method forgall stones in ultrasonography. In America $10-25 \%$ of adult population suffer from cholelithiasis. In other words we can say that 1025 million Americans have gall/stone. In US an estimated 1092 gallstones related deaths has occur in 2004. Only 1-2\% of the people with gall stone will develop complications. The sickle cell disease is associated with pigment gall stone. The prevelance of gall stone is high in American $16.6 \%$ in women and $8.6 \%$ in men. Incidence and their admixtures are also at high risk. The lowest frequencies occur in Black Africans $(<5 \%)$. The frequency of hepatolithiasis, as a proportion of all bile duct stone is $20 \%$ in China and Taiwan and $2 \%$ in Japan, Singapore and Honkong. Use of OCP and Oestrogen replacement therapy are established risk factors for cholesterol gall stone formation. The hepatic bile secretion and gallbladder function is predominantly influenced by female sex hormones. Estrogen increses cholesterol secretion and diminishes bile salt secretion, while progestin act by reducing bile salt secretion and hampering gallbladder emptying leading to stasis.

\section{Family History and Genetics}

There is a marked influence of genetic factor in the gallstone formation. It is found the risk of stone formation 


\section{International Journal of Biochemistry \& Physiology}

in nearly five times is the relatives and much higher in the siblings. These rate are even higher in monozygotic twins about $12 \%$ and dizygotic twin at $6 \%$.

\section{Gender and Female Sex Hormone}

The females has high incidence of gallstone disease especially during the fertile years and the ratio in almost double then men. However the incidence decline fallow on to menopause in women and after which men begin to catch up. The parity, oral contraceptive use and oestrogen replacement therapy are established risk factors for cholesterol gallstone formation. It has been observed that the female sex hormones adversely influence hepatic bile secretion and gallbladder function. Oestrogen increases cholesterol secretion.

\section{Review of Literature}

Cholelithiasis (Gallstones) are hard pebble like deposits in the gallbladder. The word cholelithiasis derived from Greek word $(\mathrm{chol}=$ bile + lith $=$ stone + iasis $=$ process $)$. Gallstones generally form because the bile is saturated with either cholesterol or bilirubin then bile undergoes supersaturation, nucleation and precipitation of cholesterol monohydrate crystals and growth to stone-size aggregates [14]. Initially there is always the formation of a biliary sludge which contains mucus gel, hydrophobic bile pigment, cholesterollecithin liquid crystals and solid cholesterol monohydrate crystals. The basic constituents being cholesterol, calcium bilirubinate and calcium carbonate. On the basis of their composition, gallstones can be divided into the following types:

\section{1) Pure gallstones (10\%)}

Cholesterol stones- are single, large ( $2-3 \mathrm{~cm}$ long), spheroidal to oval in shape and vary from light yellow to dark green or brown to bluish white in color, each often having a tiny, dark, central spot. To be classified as such, they must be at least $80 \%$ cholesterol by weight or $70 \%$, according to the Japanese- classification system [15]. In the literature the reported incidence of this type of stone varies between 5.43 $\%$ to17.3percent. Pigment stones- are multiple, small (2-5 $\mathrm{mm}$ ) and brown to jet black (dark) in color and comprise bilirubin and calcium salts that are found in bile. They contain less than $20 \%$ of cholesterol or $30 \%$, according to the Japanese-classification system [16]. In the literature the reported incidence of this type of stone varies between 1.62 $\%$ to 20 percent.

\section{2) Mixed gallstones (80\%)}

These are typically consists of $20-80 \%$ cholesterol or $30-$ $70 \%$, according to the Japanese- classification system[16], calcium carbonate, calcium bilirubinate, palmitate phosphate and other bile pigments. Because of their calcium content, they are often radiographically visible. These are usually multiple, faceted, laminated and vary in size \& numbers. In the literature the reported incidence of this type of stone varies between $59 \%$ to $90.8 \%$.

\section{3) Combined gallstones (10\%)}

These are characteristically large and single. They may have a pure nucleus with a mixed shell or the reverse. Barrel stones, a type of combined stone, are usually two in number, large and faceted on one surface and the thick walled gallbladder is closely wrapped around them. In the literature the reported incidence of this type of stone varies between $0.54 \%$ to $25 \%$.

The physicians of Unani medicine have dealt with temperament in detail and they defined it to the best of their knowledge and concepts. The Arab medical authors worked on the theory of temperament most assiduously and its description is found in the Arab medical literature under the heading "mizaj".

Ali Ibn Abbas Majoosi has defined the mizaj: "All sorts of bodies (light or heavy), which are found in this ever-changing world are formed by four elements (ustuqussat) after mixing in different or uniform quantities in accordance with the needs (of the body). As a result of this mixing, one or two qualities become dominant, over the body, and this is called 'mizaj'. It is derived from Arabic word 'imtizaj', meaning 'to mix with each other" [17].

Abu Sehal Masihi describes temperament as: "Because there are so many primary components (ustuqussat) of the body which are mixed together not in close proximity, it is necessary that the qualities of primary components must be mixed as a whole new qualities arise from inter-mixing of primary components which will be in between the previous qualities, called mizaj" [18].

Ibn Sina says "The temperament is that quality which results from the mutual interaction and interpassion of the four contrary primary qualities residing within the imponderable elements. These elements are so minutely intermingled as each to lie in very intimate relationship with the other. Their opposite powers alternately conquer and become conquered until a state of equilibrium is reached which is uniform throughout the whole; it is this outcome that is called as mizaj" [19].

Ibn Sina further writes that "Since the primary properties in the aforesaid elements are four namely hotness, coldness, moistness and dryness, it is obvious that the temperaments of the integrating bodies are the products of these very properties" [20]. 


\section{International Journal of Biochemistry \& Physiology}

Ismaeel Jurjanee writes about mizaj that: "When different qualities of elements acts and reacts by their powers then previous qualities become diminished and a new moderate quality is developed which is known as mizaj" [21].

Galen says that: "Temperament is a quality produced by action and reaction of opposite qualities of body fluids (Akhlat). When these components interact by virtue of their respective powers (qualities) a condition is achieved which is found in equal proportions in all the components of that intermixture; this is called temperament" [22]. It may also be noted that the Galen's concept of temperament was founded on the humors while the elemental interpretation of temperament was dominant among Arab physicians. [23].

Dawood Antaqi gives his view that: "Mizaj is a uniform quality which originates by eth action and reaction of four elements which divided into smaller particles so that the maximum particles of each can mix with each other" [24].

Ayyub Israili explains the mizaj in following words: "Mizaj is such type of moderate quality which is originated by the action and reaction of different opposite particles. When elements mix with each other and one element affects the other then they break into small particles due to action and reaction process. This process should be of such type that the biochemical structure of each element breaks the strength of quality of other elements, resulting in generation of a moderate secondary quality. This moderate secondary quality is known as mizaj" [25].

Allama Sadidi writes that: "Mizaj is such type of malmoosa (touching) quality which is produced by the effects of different qualities of smaller particles of elements and the character to adopt the effects of these different qualities" [26].

Ibn-e-Habal Baghdadi states that: "When elements get admixed, most of the elements mix with each other and their various qualities act and react so heat breaks the cold and cold breaks the heat. Similarly dryness try to breaks wetness and wetness try to breaks dryness. Low grade Qualities mix with high grade qualities light weight Particles mix with heavy weight Particles until a new Quality is developed which is equally found in all the components of elements this new and moderate Quality is known as mizaj" [27].

Allama Nafees says that: "When elements mix with each other they act and reacts which result in developing a new moderate Quality in between the all four previous Qualities and new Quality is known as mizaj" [28].

Narain Says that: The word temperament is derived from the Latin verb 'tempero' meaning to mix' or temper" [29].
Gruner says that Arabic word mizaj contains the idea of mixture', medical translators used the word complexion which carry the idea of mixing or blending or weaving" [8].

\section{Classification of Temperament According to Humours}

The human body, as Greco-Arab system of Medicine quote, comprises four body fluids namely -Dam (blood), Balgham (phlegm), Safra (yellow bile) and Sauda (black bile), constituted by initiation of different proportion of all four arkan. Dam is hot and wet in temperament, Balgham is cold and wet, Safra is hot and dry and Sauda is cold and dry. The temperament of a man is characterized both by the fluid element and its physiological and physiognomic effects, and it is expressed by the preponderance of a particular khilt present in his body. Thus a man may be damwi (sanguineous), Balghami (phlegmatic), Safravi (choleric) or Saudawi (melancholic) in nature according to the preponderance of dam, balgham, safra or Saudawi respectively. The characteristic features of four types of temperaments are as follows:

\section{The Four Temperament Types of Hippocrates 1. Sanguine Temperament (Damwi Mizaj)}

These people have hot and moist temperament, tall, strong and muscular body, broad chest, large and strong bones and well-formed joints, reddish complexion, thick, black and straight hair which shows rapid growth, mildly prominent veins, full and strong pulse. According to Ibn Sina they have slight feeling of heaviness in their body especially at the base of the eyes, head and temple. They get troubled with hot environment and food. They feel comfortable with cold and dry things and like cold weather [20,17]. Their digestive power is wonderfully good; the appetite keen, sleep sound, excreted urine is concentrated and in moderate quantity, physical activity and speech are average, psychological aggressiveness and psychic condition comes on easily and easily lost, mental condition is good, in dream red object are seen frequently and the general health is remarkably sound [30].

The sanguineous individual looks everything from the bright side. He is optimistic and is always sure of success. He is extrovert and makes acquaintance with other people [7].

\section{Choleric Temperament (Safrawi Mizaj)}

These peoples have hot and dry temperament, a medium stature, thin and hairy body, moderate musculature, deficient fat, well-formed and prominent joints, yellowish complexion, thick, curly, black, rough and abundant hairs, prominent Veins, strong and rapid pulse. They pass fiery and yellow urine. Sometimes, they feel sensation of pain and pricks over the body $[20,30]$. They feel comfortable with cold things and 


\section{International Journal of Biochemistry \& Physiology}

get troubled with hot things. Their most suitable weather is winter. The bilious (safrawi) temperament manifested a short response delay, but the response is sustained for a relatively longer time [9].

Their digestive organs are active, appetite is good and sleep is light and often disturbed. According to Ahmad, these people are proud, revengeful, shrewd, and zealous and get angry quickly. They are also energetic and intelligent individuals with a strong inclination to indulge in sexual pleasure [31].

\section{Phlegmatic Temperament (Balghami Mizaj)}

They have cold and moist temperament, flaccid and obese body built with soft and flabby muscles, flat chest, large and not well formed joints, whitish complexion, thin, straight, brownish or whitish hairs which shows slow growth, not prominent blood vessels, and soft, slow and infrequent pulse. Their urine is colourless and more in quantity. They experience excessive heaviness of the body. Their movements and activities are sluggish. Their functions like digestion, appetite and thirst are poor, sleep is excessive, memory is bad and irretentive and their power of imagination and perception is slow and feeble. These people feel comfortable with the use of hot and dry things and in hot weather. They are sexually frigid and also do not get angry easily [30-32]. The phlegmatic (balghami) temperament is characterized by a longer response delay but the response is also short-lived [9].

\section{Melancholic Temperament (Saudawi Mizaj)}

They have cold and dry temperament. They are characterized by lean and thin built with narrow chest, coarse and rough skin. Body hairs are profuse and the complexion is dark. Hairs are black, thin but have slow growth. According to Ahmad, the blood vessels are narrow and pulse is slow. Their digestion is weak and has irregular appetite. They have interrupted sleep and often suffer from insomnia. Their sense is acute and excellent memory. Hock observed that the individuals of this temperament are irresolute, reserved, despondent without courage, slow and awkward. He further writes, "The melancholic is a man of missed opportunities." They show sluggish inclination towards sexual activity $[1,7]$.

They experience excess of evil thought and anxieties. The melancholic temperament exhibit along response delay and the response is sustained at length, if not, seemingly permanently [9].

\section{Gall Bladder}

It is a flask (pear) shaped blind-ending diverticulum or hollow viscous (sac), with a muscular wall. In life, it is greyblue in colour, situated obliquely in a non-peritoneal fossa on the under surface of the right lobe of the liver. It extends from the right end of porta hepatis to the inferior border of liver. It is $7-10 \mathrm{~cm}$ ( 3 to 4 inches) long, $3-4 \mathrm{~cm}$ broad at its widest part and about 30 to $50 \mathrm{ml}$ in capacity1. The gallbladder is divided into the following regions: funds, body and neck. The portion of body that joins the neck is referred to the infundibulum; sometimes there is a small bulge in this region, known as Hartmann pouch1. Neck continues as cystic duct and is marked by a constriction. The gallbladder varies in size and shape. The fundus may be elongated and highly mobile. Rarely, the fundus is folded back upon the body of the gallbladder and is called Phrygian cap, on ultrasound this may be wrongly interpreted as an apparent septum within the gallbladder [33].

\section{Function}

- Reservoir of bile.

- Concentrates bile (5to10 times).

- Bile helps in emulsification and absorption of fats.

- Bile helps in eliminating bilirubin, a product of haemoglobin metabolism.

\section{History of Gallbladder}

Roman anatomist Galen: He identified the gall bladder and spleen as the two crucial subsidiary organs of the liver. All three organs worked together to produce and store three of the four humors of the body: blood (liver), yellow bile (gall bladder) and black bile (spleen).

Berengario: Suggested that the gallbladder regulated the emotions by being a repository for gall.

Harvey described the liver as a "noble organ" in 1653 and the spleen as an "ignoble organ" the gall bladder as "a very long pear compressed from base into neck".

\section{Society and Culture}

To have 'gall' is associated with bold behaviour, whereas to have 'bile' is associated with bitterness5. In the China, the gallbladder is associated with courage and a plethora of related idioms, including using terms such as "a body completely of gall to describe a brave person, and "single gallbladder hero" to describe a lone hero [34].

\section{Comparative Anatomy}

Most vertebrates have gallbladders, whereas invertebrates do not. However, its precise form and the arrangement of the bile ducts may vary considerably. Several species of mammals (including horses, deer, rats etc.) [35] and several species of birds lack a gallbladder altogether, as do lampreys [36].

\section{Pathophysiology}

Cholesterol gallstones develop when bile contains too much cholesterol and not enough bile salts. Besides a high concentration of cholesterol, two other factors are important in causing gallstones. The first is how often and how well the gallbladder contracts. Incomplete and infrequent emptying 


\section{International Journal of Biochemistry \& Physiology}

of the gallbladder may cause the bile to become over concentrated and contribute to gallstone formation. This can be caused by high resistance to the flow of bile out of the gallbladder due to the complicated internal geometry of the cystic duct [37]. The second factor is the presence of proteins in the liver and bile that either promote or inhibit cholesterol crystallization into gallstones.

In addition, increased levels of the hormone estrogen, as a result of pregnancy or hormone therapy, or the use of combined (estrogen - containing) forms of hormonal contraception, may increase cholesterol levels in bile and also decrease gallbladder movement, resulting in gallstone formation. Sequential cholecystographic studies and carbon-14 dating suggest that gallbladder stone grow at a rate of approximately $1-2 \mathrm{~mm}$ / year and that they are usually present for 5-20 years before they are removed [15].

Number of stones: Gallstones are present in single, double and multiple numbers. In the available literature the incidence of single stone varied from $\%$ to $39.6 \%$ cases, double stones in $8.8 \%$ cases and multiple stones from $51.6 \%$ to $93 \%$ cases [38].

Sex ratio: All the available studies suggest that the females are more prone to gallstone than males. In the review male and female ratio (M: F) range between1:1.4 to 1:7.3 [39].

Size: The maximum gallstone size of $4.0 \mathrm{~cm}$ was observed in cases of malignancy (Narang et al 2014)13. Mathur et al 2012 has reported the gallstone size to be $2.147 \mathrm{~cm}$ in cases with carcinoma, followed by hyperplasia $1.187 \mathrm{~cm}$, metaplasia $1.145 \mathrm{~cm}$ and cholecystitis $1.136 \mathrm{~cm}$ [40].

Volume: The average volume of the gallstone was $2.664 \mathrm{ml}$ in cholecystitis, $3.742 \mathrm{ml}$ in hyperplasia, $4.532 \mathrm{ml}$ in metaplasia and $19.178 \mathrm{ml}$ in carcinoma as reported by Mathur, et al. [41]. Age: Stones are found in patients with age range between 23 to 76 years [42].

\section{Materials \& Methods}

This study was carried out in the department of Munefe- ul-aaza at Deoband Unani Medical Collage, Deoband. Hundred cholelithiasis patient of either sexes having damvi, balghami, saudawi and safrawi temperament were randomly selected for the study.

Inclusion criteria: Damvi, balghami, saudawi and safrawi patients in the age group of 20 to 60 years will include in the study.

Exclusion Criteria: Patient below 20 year and above 60 year.

Patient having other diseases likes Malnutrition, Diabetes Mellitus, Hyperthyroidism, Hypothyroidism, Tuberculosis or any disease that influence spleen size.

Athletic activities, heavy exercise, Radiotherapy, Chemotherapy, major accident and surgery or taking steroids for long period.

\section{Determination of Temperament (Mizaj)}

The assessment of Mizaj (temperament) of the volunteers were made on the basis of a self-designed proforma (questionnaire) prepared in the light of criteria described in classical Unani literature (Ajnas-e-Ashra).

\section{Categorization of Volunteers}

The selected volunteers were divided into two groups according to their temperament.

Group A: Damvi (Sanguine) temperament

Group B: Balgami (Phlegmatic) temperament

Group C: Safrawi (Choleric) temperament

Group D: Saudawi (Melancholic) temperament

The temperament of the volunteers was assessed on the basis of Ajnas-e-Ashra, mentioned in classical Unani literature.

\section{Objective of Study}

To evaluate the frequency and distribution of the Cholelithiasis (Gallstone) among four differenttemperaments Damwi, Balghami, Safrawi, Saudawi and to explore the size of stone among different temperaments.

\section{Distribution of Patients and Observation}

\section{1) Distribution of Volunteers according to Mizaj}

\begin{tabular}{|c|c|}
\hline Temperament & Frequency \\
\hline Sanguine & 20 \\
\hline Choleric & 40 \\
\hline Phlegmatic & 35 \\
\hline Melancholic & 5 \\
\hline Total & $\mathbf{1 0 0}$ \\
\hline
\end{tabular}

Table 1: Showing distribution of Mizaj. 


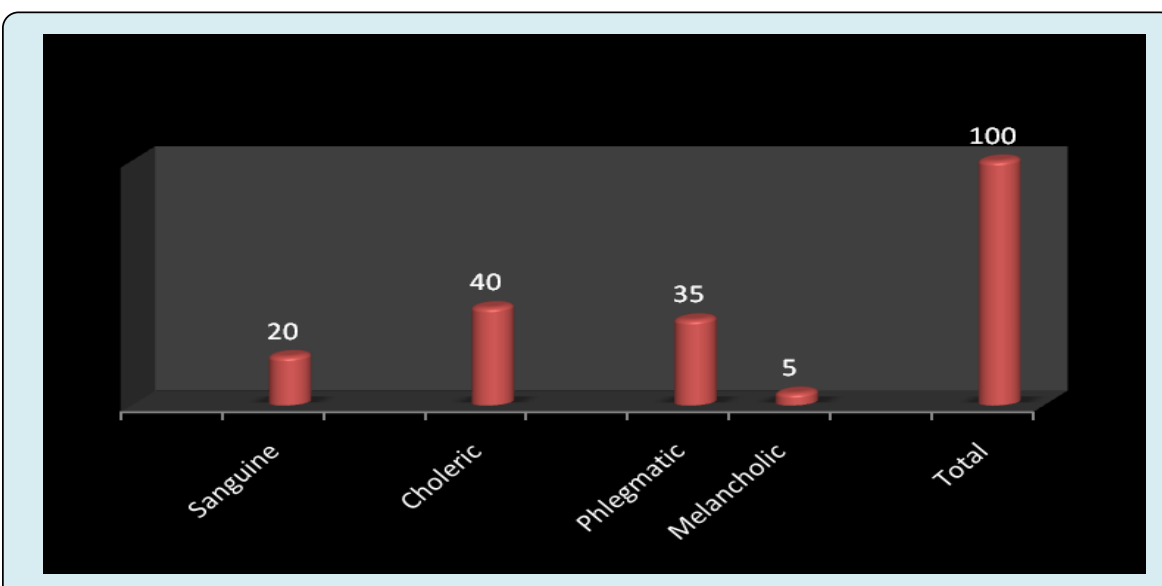

Figure 1: Distribution of Volunteers according to Mizaj.

2) Showing Distribution of Volunteers according to Age

\begin{tabular}{|c|c|c|c|}
\hline Age Group & Number of Patients & Male & Female \\
\hline $20-30$ & 17 & 1 & 16 \\
\hline $31-40$ & 30 & 3 & 27 \\
\hline $41-50$ & 32 & 3 & 29 \\
\hline $51-60$ & 21 & 2 & 19 \\
\hline Total & $\mathbf{1 0 0}$ & $\mathbf{9}$ & $\mathbf{9 1}$ \\
\hline
\end{tabular}

Table 2: Showing Distribution of Age.

1) Showing Distribution of Volunteers according to Heights

\begin{tabular}{|c|c|c|c|c|c|}
\hline Standing Height in mm & Sanguine & Choleric & Phlegmatic & Melancholic & Total \\
\hline $1625-1650$ & 4 & 23 & 8 & 0 & 35 \\
\hline $1651-1675$ & 5 & 7 & 6 & 5 & 23 \\
\hline $1676-1700$ & 7 & 10 & 4 & 5 & 26 \\
\hline $1701-1725$ & 4 & 10 & 2 & 0 & 16 \\
\hline Total & $\mathbf{2 0}$ & $\mathbf{5 0}$ & $\mathbf{2 0}$ & $\mathbf{1 0}$ & $\mathbf{1 0 0}$ \\
\hline
\end{tabular}

Table 3: Showing Distribution of Heights

2) Showing Distribution of Volunteers according to Weights

\begin{tabular}{|c|c|c|c|c|c|}
\hline Weight in Kg & Sanguine & Choleric & Phlegmatic & Melancholic & Total \\
\hline $45-55$ & 3 & 7 & 2 & 0 & 12 \\
\hline $56-65$ & 6 & 20 & 4 & 5 & 35 \\
\hline $66-75$ & 7 & 10 & 6 & 0 & 28 \\
\hline $76-85$ & 4 & 13 & 8 & 5 & 25 \\
\hline Total & $\mathbf{2 0}$ & 50 & 20 & 10 & 100 \\
\hline
\end{tabular}

Table 4: Showing Distribution of weight. 
3) Indicating Endomorph in different temperament of volunteers expressed as Mean $\pm \mathrm{SD}^{*}$

\begin{tabular}{|c|c|c|}
\hline Temperament & Number of Volunteers & Mean \pm SD \\
\hline Sanguine & 20 & $3.36 \pm 0.64$ \\
\hline Choleric & 40 & $2.45 \pm 0.98$ \\
\hline Phlegmatic & 35 & $4.45 \pm 0.72$ \\
\hline Melancholic & 5 & $1.13 \pm 0.01$ \\
\hline Total & 100 & $3.64 \pm 0.91$ \\
\hline
\end{tabular}

Table 5: Showing endomorph expressed as Mean \pm SD.

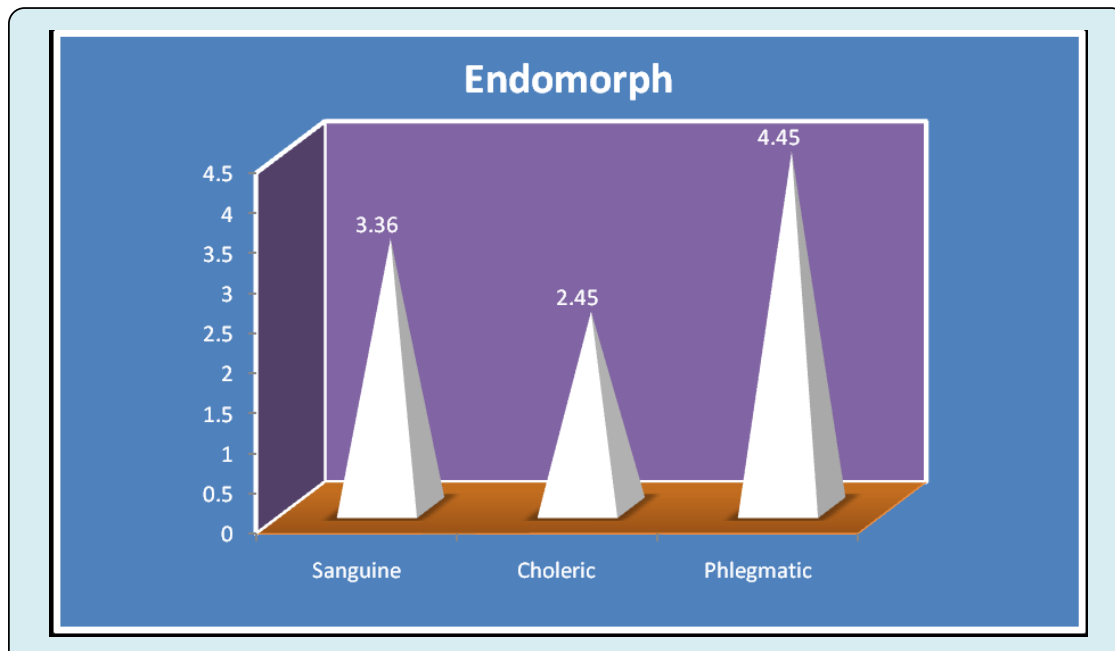

Figure 2: Showing endomorph expressed as Mean \pm SD.

\section{Comparison of Endomorph between different Temperaments}

\begin{tabular}{|l|l|}
\hline Temperaments & Significance \\
\hline Sanguine Vs Choleric & $\mathrm{t}=1.5, \mathrm{p}>.05$ \\
\hline Choleric Vs Phlegmatic & $\mathrm{t}=2.9, \mathrm{p}<.05$ \\
\hline Choleric Vs Phlegmatic & $\mathrm{t}=1.6, \mathrm{p}>.05$ \\
\hline
\end{tabular}

Significant at the level of $p<.05$

Table 6: Showing comparison of endomorph in different temperament.

5) Indicating Ectomorph of Volunteers expressed as Mean $\pm \mathrm{SD}^{*}$

\begin{tabular}{|l|l|l|}
\hline Temperaments & Number of Volunteers & Mean \pm SD* \\
\hline Sanguine & 20 & $2.11 \pm 0.45$ \\
\hline Choleric & 40 & $3.11 \pm 0.77$ \\
\hline Phlegmatic & 35 & $1.91 \pm 0.78$ \\
\hline Melancholic & 5 & $1.90 \pm 0.88$ \\
\hline Total & $\mathbf{1 0 0}$ & $\mathbf{2 . 1 5} \pm \mathbf{0 . 7 8}$ \\
\hline
\end{tabular}

Table 7: Showing ectomorph expressed as Mean \pm SD.

Volunteers Mean $\pm \mathrm{SD}^{*}$ 


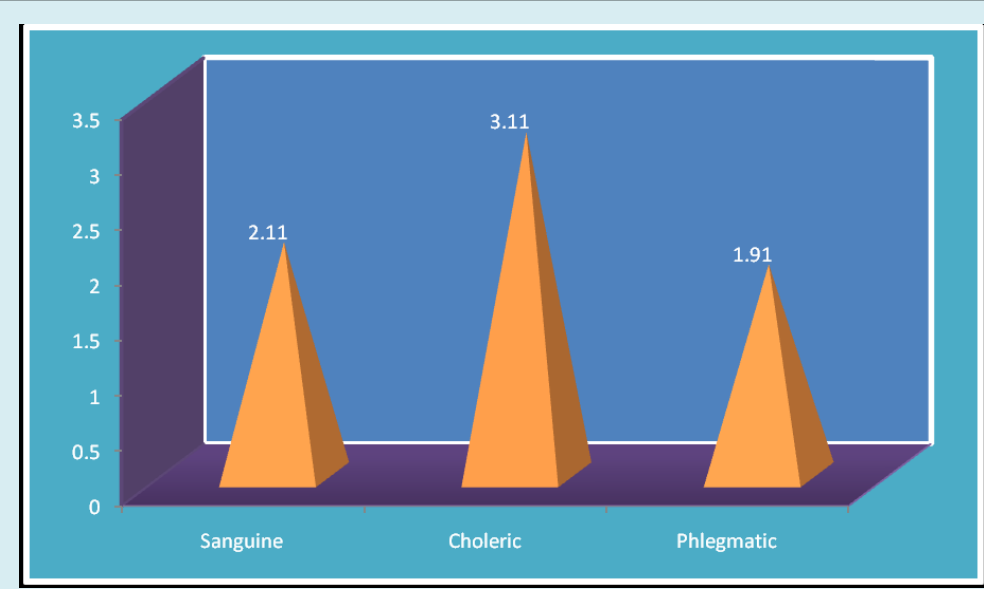

Figure 3: Showing comparison of ectomorph in different temperament.

6) Showing Comparison of Ectomorph between different Temperaments

\begin{tabular}{|l|l|}
\hline Temperaments & Significance \\
\hline Sanguine Vs Choleric & $\mathrm{t}=5.9, \mathrm{p}<.001$ \\
\hline Sanguine Vs Phlegmatic & $\mathrm{t}=5.2, \mathrm{p}<.001$ \\
\hline Choleric Vs Phlegmatic & $\mathrm{t}=5.0, \mathrm{p}<.001$ \\
\hline \multicolumn{2}{|c|}{ Significant at the level of $p<.05$}
\end{tabular}

Table 8: Showing ectomorph comparison in different temperament.

Indicating Descriptive Statistics of Somatotypes of Sanguine Volunteers

\begin{tabular}{|c|c|c|}
\hline Somatotypes & Number of Volunteers & Mean \pm SD $^{*}$ \\
\hline Endomorph & $\mathbf{3 5}$ & $3.36 \pm 0.64$ \\
\hline Mesomorph & $\mathbf{4 0}$ & $4.40 \pm 0.60$ \\
\hline Ectomorph & $\mathbf{2 5}$ & $2.11 \pm 0.45$ \\
\hline \multicolumn{3}{|c}{${ }^{*}$ Standard Deviation }
\end{tabular}

*Standard Deviation

Table 9: Showing somatotypes in sanguine volunteers.

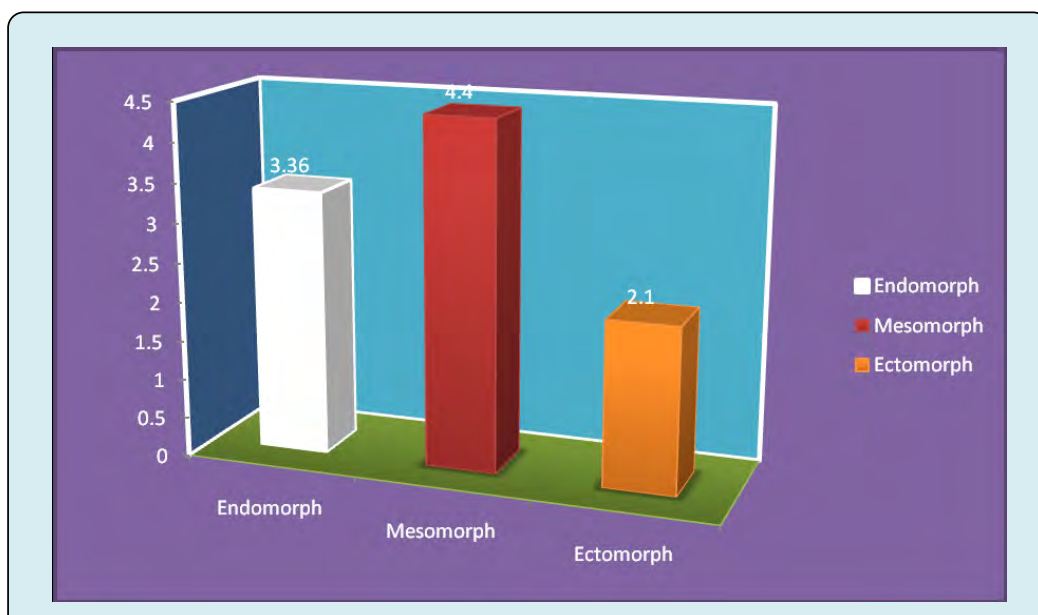

Figure 4: Showing somatotypes in sanguine volunteers. 
8) Showing Comparison of Somatotypes in Sanguine Individuals

\begin{tabular}{|l|l|}
\hline Somatotypes & Mean \pm SD $^{*}$ \\
\hline Endomorph Vs Mesomorph & $\mathrm{t}=5.5, \mathrm{p}<.001$ \\
\hline Endomorph Vs Ectomorph & $\mathrm{t}=7.3, \mathrm{p}<.001$ \\
\hline Mesomorph Vs Ectomorph & $\mathrm{t}=13.5, \mathrm{p}<.001$ \\
\hline
\end{tabular}

Significant at the level of $p<.05$

Table 10: Showing comparison of somatotypes in sanguine volunteers.

9) Indicating Descriptive Statistics of Somatotypes of Choleric Volunteers

\begin{tabular}{|c|c|c|}
\hline Somatotypes & Number of Volunteers & Mean \pm SD* $^{*}$ \\
\hline Endomorph & $\mathbf{4 0}$ & $2.45 \pm 0.98$ \\
\hline Mesomorph & $\mathbf{3 5}$ & $4.10 \pm 0.65$ \\
\hline Ectomorph & $\mathbf{2 5}$ & $3.11 \pm 0.77$ \\
\hline
\end{tabular}

*Standard Deviation

Table 11: Showing comparison of somatotypes in choleric volunteers.

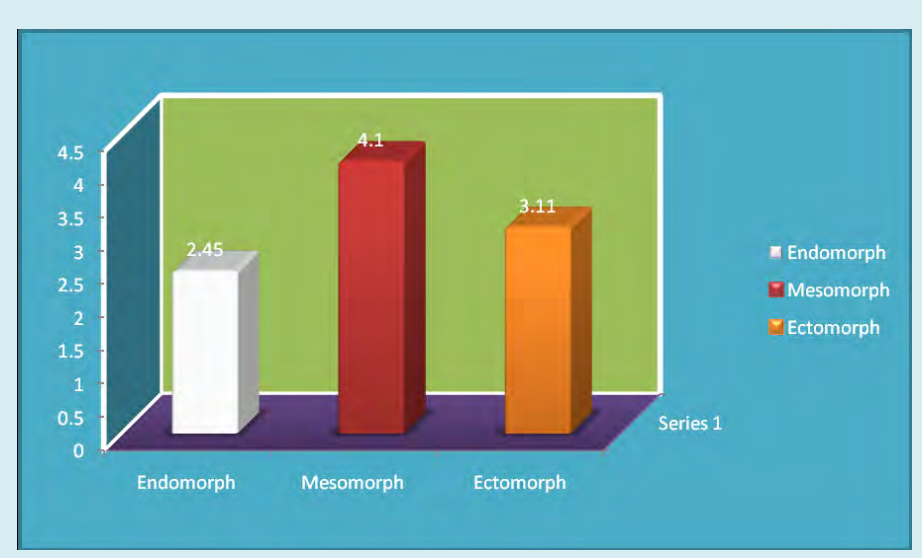

Figure 5: Showing mean Difference of Somatotypes in Choleric Temperament.

Comparison of Somatotypes in Choleric Individuals

\begin{tabular}{|l|l|}
\hline Somatotypes & Significance \\
\hline Endomorph Vs Mesomorph & $\mathrm{t}=3.3, \mathrm{p}<.001$ \\
\hline Endomorph Vs Ectomorph & $\mathrm{t}=3.4, \mathrm{p}<.05$ \\
\hline Mesomorph Vs Ectomorph & $\mathrm{t}=5.5, \mathrm{p}<.001$ \\
\hline
\end{tabular}

Significant at the level of $p<.05$

Table 12: Showing comparison of somatotypes in choleric volunteers.

11)

Indicating Descriptive Statistics of Somatotypes of Phlegmatic Volunteers

\begin{tabular}{|l|l|l|}
\hline Somatotypes & Number of Volunteers & Mean \pm SD $^{*}$ \\
\hline Endomorph & $\mathbf{4 0}$ & $4.45 \pm 0.72$ \\
\hline Mesomorph & $\mathbf{3 5}$ & $3.72 \pm 0.82$ \\
\hline Ectomorph & $\mathbf{2 5}$ & $1.91 \pm 0.78$ \\
\hline \multicolumn{2}{|c}{} \\
\hline
\end{tabular}

Table 13: Showing descriptive statistics of somatotypes in phlegmatic volunteers. 


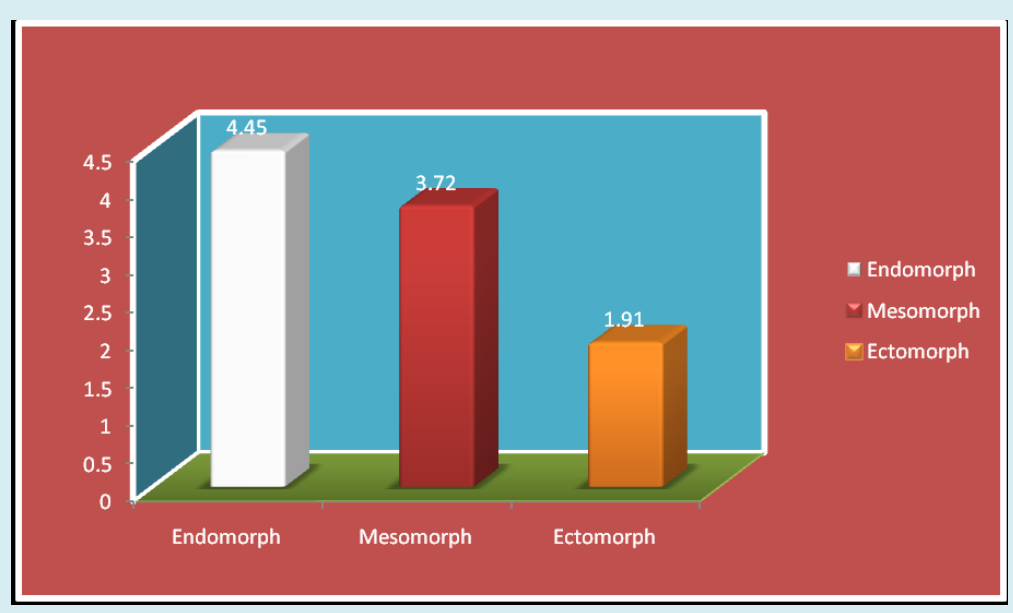

Figure 6: Showing mean difference of somatotypes in phlegmatic temperament

12)

Showing Comparison of Somatotypes in Phlegmatic Volunteers

\begin{tabular}{|c|c|}
\hline Somatotypes & Significance \\
\hline Endomorph Vs Mesomorph & $\mathrm{t}=3.0, \mathrm{p}<.01$ \\
\hline Endomorph Vs Ectomorph & $\mathrm{t}=10.6, \mathrm{p}<.001$ \\
\hline Mesomorph Vs Ectomorph & $\mathrm{t}=7.2, \mathrm{p}<.001$ \\
\hline
\end{tabular}

Significant at the level of $p<.05$

Table 14: Showing comparison of somatotypes in phlegmatic volunteers.

13)

Incidence of gall-stone in either sex

\begin{tabular}{|l|l|l|}
\hline Male & Female & Total \\
\hline 9 & 91 & 100 \\
\hline
\end{tabular}

Table 15: Showing incidence of gall stone in either sex.

Relation between incidence of gall-stones and number of conceptions

\begin{tabular}{|c|c|c|}
\hline Conceptions & Number of Patients & Percentage \\
\hline $0-3$ & 5 & $5.05 \%$ \\
\hline $3-6$ & 41 & $45.45 \%$ \\
\hline $6-9$ & 34 & $39.39 \%$ \\
\hline $9-12$ & 9 & $8.08 \%$ \\
\hline $12-15$ & 2 & $2.02 \%$ \\
\hline Total & $\mathbf{9 1}$ & $\mathbf{1 0 0}$ \\
\hline
\end{tabular}

Table 16: Showing relation between incidence of gall-stones and number of conceptions.

\section{Discussion}

The concept of temperament is one of the major component of Unani medicine on which health or disease condition of human being are based. Diagnosis, treatment and prevention from diseases, is also determined by the temperament assessment. Every person possesses a unique temperament which includes his physical characteristics' physiological and anatomical profile as well as emotional state which attribute to Mizaj. Temperament is an empirical expression of humoural composition that regulates the physiology and structural pathology in human being, each individual's temperament is said to posses' innate strength and deficiency for which they react differently to given set 


\section{International Journal of Biochemistry \& Physiology}

of environmental condition. As a consequence tends more towards disease of particular types require different type of diet and life style for healthy living and even different type of drugs to get rid of disease. Unani physicians have described several parameters for the determination of temperament. However the most acceptable and appropriate parameters have been given by Ibn-e-Sina that are ten in number and are applied and used universally for the assessment of temperament. Among these, haiyat al- aza'a is very important and significant parameter to assess the temperament. The Hayat al-aza'a or body physique is described as a branch of Unani medicine which deals with the study of shape, size, structure and appearance of human body as a whole or its parts. The study and measurements of Hayat al-aza'a may be used not only in assessing temperament but also to determine differences among individuals, groups etc.

In this study the size of stone were measured with the help of ultrasonography. After taking all measurements, all the scores were sequentially arranged into a tabular format and for the mean and standard deviation of scores therefore statistical analysis was applied to establish size of stone variation between means of the phlegmatic and bilious temperaments, Student t- Unpaired test was applied. The results are discussed below:

1. The total number of volunteers in this study were hundred in number, out of which forty were Bilious and thirty five were phlegmatic temperaments twenty were Sanguine and five were melancholic, with equal percentage of distribution (Table 1 and Figure 1).

2. The selected age group was 20-60 years, which was subdivided in four groups as 20-30, 31-40, 41-50 and 5160 years respectively. In the age group of 20-30 years, 17 (17\% of total) volunteers were found whereas age group of 31-40years, 30 (30\% of total) volunteers were found, whereas age group of 41-50 years, 32 (32\% of total) and in age group 51-60 years 21 (21\% of total) volunteers were found respectively. If we see over in both temperaments the majority of volunteers were found in age group of 41-50 years which comprises 32\% (Table 2).

3. Height of volunteers were subdivided into four sub groups, $1625-1650 \mathrm{~mm}, 1651-1675 \mathrm{~mm}, 1676-1700$ $\mathrm{mm}$ and $1701-1725 \mathrm{~mm} .35$ (35\% of total) volunteers possess their height $1625-1650 \mathrm{~mm}$ and $23(23 \%$ of total) volunteers have height range 1651- $1675 \mathrm{~mm}$., 26 (26\% of total) volunteers possess their height $1676-$ $1700 \mathrm{~mm}$. and in ranges from $1701-1725 \mathrm{~mm}$ height the number of volunteers are 16 (16\% of total). By above data it was observed that the majority of all the four groups' volunteers were found in height range of 1625$1650 \mathrm{~mm}$ which is $35 \%$ in which bilious and $65.71 \%$ (Table 3).

4. Volunteers were also observed according to their weight.
Volunteers were divided into four sub groups according to their weight as $45-55 \mathrm{~kg}, 56-65 \mathrm{~kg}, 66-75 \mathrm{~kg}, 76-85$ Kg. 12 (12\% of total) volunteers possess their weight $45-$ $55 \mathrm{~kg}, 35$ (35\% of total) volunteers have weight range $56-65 \mathrm{~kg}, 28$ (28\% of total) volunteers have weight range $66-75 \mathrm{~kg}$ and 25 (25\% of total) comes under the ranges from 76-85 $\mathrm{kg}$ of weight. The majority of all the four groups' volunteers were found in weight group of 56- $65 \mathrm{~kg}$ which comprises $57.14 \%$ bilious temperament (Table 4).

5. It provides the scientific evidence for the theory of temperament in context of haiyat-al aza'a. Indicating endomorph in different temperament of volunteers as shown in Table 5 and Figure 2.

6. Comparison of endomorph between different temperaments such as Sanguine vs choleric, choleric vs phlegmatic and choleric vs phlegmatic are showing in Table 6.

7. Indicating ectomorph of volunteers expressed as Mean \pm SD of sanguine $2.11 \pm 0.45$, choleric $3.11 \pm 0.77$, phlegmatic $1.91 \pm 0.78$ and melancholic $1.90 \pm 0.88$ shown in Table 7, Figure 3.

8. Indicating comparison of ectomorph between different temperaments as sanguine vs choleric $(\mathrm{t}=5.9, \mathrm{p}<.001)$, sanguine vs phlegmatic $(t=5.2, p<.001)$ and choleric vs phlegmatic $(t=5.0, p<.001)$ are shown in Table 8 .

9. Indicating descriptive statistics of somatotypes of sanguine volunteers as Endomorph $(3.36 \pm 0.64)$,

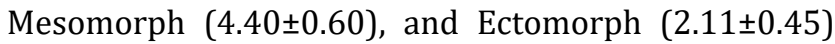
shown in Table 9, Figure 4.

10. Showing comparison of somatotypes in sanguine individuals shown in Table 10.

11. Indicating descriptive statics of somatotypes of choleric volunteers in which endomorph is in highest in number Table 11, Figure 5.

12. Indicating comparison of somatotypes in choleric individuals are shown in Table 12.

13. Indicating descriptive statistics of somatotypes of phlegmatic volunteers shown in Table 13, Figure 6.

14. Indicating comparison of somatotypes in phlegmatic volunteers and its significance (Table 14).

15. Indicating gender distribution of gall stone which are $91 \%$ of total cases are female (Table 15).

16. Indicating relation between incidence of gall stone and number of conceptions in which 3-6 conceptions are highest number of patients (Table 16).

Present study has ensured that the result is in accordance with Unani philosophy which says that the persons of hot temperament have well developed external as well as internal organs while the person of cold temperament possess opposite characteristics. Therefore it is concluded that the person who contributes high value of size of stone would be of Bilious temperament, person having low value of size of 


\section{International Journal of Biochemistry \& Physiology}

stone would be of Melancholic temperament. Suggestions for Further Research Researches and explorations are not the end results but there always open the way for future investigation. Similarly, the present work is not the end in this area. The results of the present investigation led to certain possibilities for further researches. The present research work was confined to only 100 volunteers. Thus it cannot claim for its comprehensiveness. Larger sample can provide better results. So future research can be conducted on larger sample. The result of such studies can provide greater insight for the determination of temperament. The present research work is confined to study the relationship of size of stone for bilious and phlegmatic temperaments only. Further researches may be conducted to explore the other variables like width, volume etc. of spleen not only in bilious and phlegmatic but in all four temperaments. It may provide validation method for the determination of temperament. Moreover, demographic variables may give some interesting findings.

\section{Conclusion}

The study revealed that the patients with bilious (Choleric) temperament are more prone to cholelithiasis followed by phlegmatic, Sanguine and then melancholic and it has also been found that the size of the stone in bilious persons is found larger in size in comparison to that of phlegmatic ones which lends the scientific basis to the theory of Unani system of medicine that individuals of hot temperament have broader, larger, and well developed body structures. Smaller sample size and limited resources were the study limitations. Hence, it is recommended that more studies on the said subject may be conducted applying newer scientific modalities to further strengthen the study result.

\section{Acknowledgement}

Authors are duly acknowledge the Director, Principal and Hospital staff of Deoband Unani Medical College, Deoband.

Conflict of Interest: There is no any conflict of Interest.

\section{References}

1. Glenn F (1963) Historical consideration, In: Atlas of Biliary Tract Surgery, New York; The Macmillan Co. Publishers, pp: 853-854.

2. Thudichum JLWA (1863) Treatise of Gallstones, London, J. Churchill and Sons, pp: 975.

3. Tabari FH (1981) (Translated in Urdu by Hakeem Rasheed Ashraf Nadvi), Matba Hamdard Foundation Press, Karachi, pp: 635-637.
4. Ali Ibn Abbas Majusi, (129-H). Kamailus-Sana-atitTabiya, I(1): 376-77.

5. Razi A. B. M. B. Z. Al-Havi Kabir (Arabic) (1968) Daeratul Maarif Osmania, Hyderabad, vii: 142-43.

6. Ibn-e -HubL (1362) Kitabul Mukhtarat, Dairatul Maarif Osmania, Hyderabad, iii: 355-56.

7. (1989) Ibne Nafis B. A. B. J. K. Sharahul-Asbabe wal Alamat, Munshi Nawal Kishore, Lucknow, ii: 13-14.

8. (1925) Hakeem Mohammad Akbar Arzani. Tibbe-Akbar. Munshi Nawal Kishore Lucknow, 11: 222-263

9. (1980) Hakeem Mohammed Kabeeruddin. Tarjuma Kabeer, Hikmat Book Depot. Hyderabad, II: 306-7.

10. Bailey HH (1992) Bailey and Love's Short Practise of surgery, $21^{\text {st }}($ Edn.), pp: 853-854.

11. Rigotti A, Miquel JF, Nervi F (1991) Conceptual evolution regarding the pathogenesis of biliary lithiasis due to cholesterol calculi. Rev Med Chil 119(3): 312-20.

12. Shibamoto Y, Shibata K, Tsukie E (1993) Etiology of cholelithiasis. Nippon Rensho 51(7): 1731-736.

13. Bailey HH (2000) Bailey and Love's Short Practice of Surgery. 23 ${ }^{\text {rd }}$ (Edn), pp: 975.

14. Romer AS, Parsons TS (1977) The Vertebrate Body. Philadelphia, PA: Holt- Saunders International, pp: 355.

15. Smith BF, LaMont JT (1987) The sequence of events in gallstone formation. Lab Invest 1987, 56(2): 125- 126.

16. Kim IS, Myung SJ, Lee SS, Lee SK, Kim MH (2003) Classification and nomenclature of gallstones revisited. Yonse Medical Journal 44(4): 561-70.

17. Gruner OC (983) The Four Temperament, Avicenna's tract on cardiac drugs and essays on Arab Cardio therapy, IHMMR, New Delhi, pp: 119-123.

18. (2010) Majusi, Ali Ibn Abbas, Kamilus Sana, Urdu Translation by Ghulam Husain Kantoori, Idara kitab-ukShifa, New Delhi, pp: 25,32, 42,109,108.

19. (1963) Masihi Abul Sehal, Isa Bin Yahya Bin Ibrahim, Kitab al Meyat Fil Tib, Part- I, Islamic Publication Society, Hyderabad, pp: 82,98.

20. Azmi AA (1995) Basic Concepts of Unani Medicine-A Critical Study. $1^{\text {st }}$ (Edn.), Department of History of Medicine, Jamia Hamdard, New Delhi, pp: 57-59,73-79.

21. Ibn Sina, Al Qanoon fil Tibb (1993) Book-I, English 


\section{International Journal of Biochemistry \& Physiology}

translation of the critical Arabic Text, Jamia Hamdard, New Delhi, pp: 7-13,65,190-197

22. Jurjani AH, Zakhira Khwarizam Shahi (1902) Urdu translation by Hadi Hassan Khan, Matba Nami Nawal Kishore, Lucknow, 1: 14, 18-25.

23. Galen, Kitab Fil Anasir (2008) Edited and Translated by Zillur Rehman, International Printing Press, Aligarh, pp: 99-100.

24. Antaqi D, Tazqaratul Albab Vol-I, Matba Ata al Zahrze, Egypt, 1349 Hjri, PP: 10.

25. Jamaluddin MI, Halul Muajjaz (1907) Urdu translation by Mohd Ayyub Israili, Matba Munshi Naval Kishore, Lucknow, 1: 38,102,234

26. Gazrooni S, Kulliyat-e-Sadidi (1910) Urdu translation by Maulvi Sayyed Abid Husain, Matba Munshi Naval Kishore, Lucknow, pp: 12-189.

27. Baghdadi IH, Kitabul Mukhtarat Fil Tibb (2005) Urdu translation, CCRUM, New Delhi, 2005, pp: 149.

28. Narain R (1996) Health Care of Temperaments and Constitutional Defects, 2nd Edition, Sir Satguru Publishers Delhi, pp: X-XII,30-31,45-47,62-65.

29. Hamdani SK Hussain, Daqeeq-ul-Kulliyat (1996) SH Offset, New Delhi, pp: 54.

30. (1927) Kabiruddin M, Ifada-e-Kabir Tarjuma wa Sharah Muajuzul Qanun, Nazin Daftar Masihi, New Delhi, pp: 6263.

31. Hock RC (2013) The Four Temperament, The Angelicum Academy.

32. Hameed A (1972) Philosophy of Medicine and Science Problems and Perspectives. Complied by Department of Philosophy of Medicine and Science, IHMMR, New Delhi, pp: 6.
33. Standring S (2008) Gallbladder and Biliary Tree.G ray's Anatomy -The Anatomical Basis of Clinical Practice, $40^{\text {th }}$ (Edn.), Churchill living stone elsevier. pp: 1177.

34. (1989) The Oxford English dictionary. $2^{\text {nd }}$ (Edn.), Oxford: Clarendon Press. 1989. p. gall, bile.

35. Yu Ning (2003) Metaphor, Body, and Culture: The Chinese Understanding of Gallbladder and Courage. Metaphor and Symbol 18(1): 13-31.

36. Michael Hogan (2008) Guanaco: Lama guanicoe, Global Twitcher.com, ed. N. Strömberg.

37. Al-Atabi M, Chin SB (2010) Experimental investigation of the flow of bile in patient specific cystic duct models. J Biomech Eng 132(4): 041003.

38. Mok HYI, Druffel ERM, Rampone WM (1986) Chronology of cholelithiasis. Dating gallstones from atmospheric radiocarbon produced by nuclear bomb explosions. $\mathrm{N}$ Engl J Med 314: 1075-1077.

39. Narang S, Goyal P, Bal M S, Bandlish U, Goyal S (2014) Gall stones size, number, biochemical analysis and lipidogram-An association with gall bladder cancer: a study of 200 cases. International Journal of Cancer Therapy and Oncology 2: 1-6.

40. Mathur SK, Duhan A, Singh S, Aggarwal M, Aggarwal G, et al. (2012) Correlation of Gallstone Characteristics With Mucosal Changes In Gallbladder. Trop Gastroenterol 33(1): 39-44.

41. Baig SJ, Biswas S, Das S (2002) Histopathological Changes in Gallbladder Mucosa in Cholelithiasis: Correlation with Chemical Composition of Gallstones. Trop Gastroenterol 23: 25-27.

42. Mohan H (2005) Extra Hepatic Biliary Apparatus-Gall Bladderin. $5^{\text {th }}$ (Edn.), Text Book of Pathology, 19: 658664. 